\title{
FAKTOR-FAKTOR PENGHAMBAT MASYARAKAT DAERAH TERTINGGAL MEMPEROLEH PENDIDIKAN FORMAL Studi Kasus Jorong Bukit Lintang Nagari Malampah Kecamatan Tigo Nagari Kabupaten Pasaman
}

\author{
Misrida Aini ${ }^{1}$, Yurni Suasti ${ }^{2}$, Fitriana Syahar ${ }^{2}$. \\ Program Studi Pendidikan Geografi \\ Fakultas Ilmu Sosial, Universitas Negeri Padang \\ Email: Misridaaini@gmail.com
}

\begin{abstract}
Abstrak
Penelitian ini merupakan penelitian deskriptif kualitatif, yang bertujuan untuk mendeskripsikan faktor-faktor penghambat masyarakat daerah tertinggal memperoleh pendidikan formal dan untuk mengetahui sejauh mana peran pemerintah daerah/lembaga masyarakat dalam pendidikan masyarakat tertinggal di Jorong Bukit Lintang. Teknik pemilihan informan dilakukan secara Snowball Sampling, dengan jumlah informan 40 orang, dan untuk menjawab pertanyaan dari peran pemerintah/lembaga masyarakat dalam pendidikan masyarakat Jorong Bukit Lintang peneliti memilih informan kunci yaitu Kepala Dinas Pendidikan Kabuaten Pasaman, Wali Nagari Malampah, Kepala Jorong Bukit Lintang, Guru yang mengajar di Jorong Bukit Lintang dan tokoh masyarakat yang ada di Jorong Bukit Lintang. Teknik pengambilan data dengan observasi, wawancara dan dokumentasi. Selanjutnya dilakukan teknik analisis keabsahan data yaitu dengan mengunakan teknik triangulasi dengan memperoleh data dari subjek penelitian pada waktu, tempat dan situasi berbeda. Berdasarkan hasil temuan dilapangan maka hasil penelitian ini adalah sebagai berikut: 1) Faktor-faktor penghambat masyarakat daerah tertinggal Jorong Bukit Lintang memperoleh pendidikan formal yaitu, a) Rendahnya pandangan masyarakat daerah tertinggal di Jorong Bukit Lintang terhadap pentingnya pendidikan, b) Jauhnya jarak tempuh, minimnya transportasi dan rusaknya sarana prasarana jalan masyarakat Jorong Bukit Lintang menuju fasilitas pendidikan formal, c) Rendahnya minat anak untuk sekolah, d) Anak sangat berperan dalam memenuhi kebutuhan keluarga, dalam mangarap sawah dan ladang terutama bagi masyarakat yang memiliki lahan luas. 2) Kurangnya sarana dan prasarana sekolah di Jorong Bukit Lintang, dan kuranya peran pemerintah dan lembaga masyarakat terhadap kemajuan pendidikan masyarakat daerah tertinggal di Jorong Bukit Lintang menjadi faktor penghambat masyarakat Jorong Bukit Lintang memperoleh pendidikan formal.
\end{abstract}

Kata Kunci : Faktor-Faktor Penghambat, Daerah Tertinggal, Pendidikan Formal

\begin{abstract}
This is a qualitative descriptive, which aims to describe the inhibiting factors of the underdeveloped regions of society to obtain formal education and to know the extent to which the role of local government / community institutions in community education lags behind in Jorong Bukit Lintang. The technique of selecting the informants was conducted by snowball sampling, with 40 informants, and to answer the questions from the role of government / community institution in Jorong Bukit Lintang education, the researcher chose the key informants, namely Head of Education Office of Pasaman, village head Malampah, Jorong Bukit Lintang, Teachers who teach in Jorong Bukit Lintang and
\end{abstract}

\footnotetext{
${ }^{1}$ Mahasiswa Program Studi Pendidikan Geografi untuk Wisuda September 2017

${ }^{2}$ Dosen Jurusan Geografi Fakultas Ilmu Sosial Universitas Negeri Padang
} 
community leaders in Jorong Bukit Lintang. Technique of taking data with observation, interview and documentation. Furthermore, the technique of data validity analysis is done by using triangulation technique by obtaining data from research subjects at different times, places and situations. Based on the findings in the field, the results of this study are as follows: 1) The factors that inhibit the lagging local communities Jorong Bukit Lintang obtain formal education that is, a) The low views of the people of the disadvantaged areas in Jorong Bukit Lintang on the importance of education, b) Lack of transportation and destruction of Jorong Bukit Lintang public road infrastructure facilities to formal education facilities, c) Low interest of children for schools, d) Children play a very important role in meeting the needs of families, in mangarap fields and fields, especially for people who have large land. 2) Lack of school facilities and infrastructure in Jorong Bukit Lintang, and the declining role of government and community institutions on the advancement of education of disadvantaged areas in Jorong Bukit Lintang become the inhibiting factor for Jorong Bukit Lintang people get formal education.

Keywords: Inhibiting Factor, Disadvantaged Area, Formal Education

\section{PEDAHULUAN}

Kesenjangan pembangunan merupakan permasalahan yang kompleks dihadapi negara Indonesia. Permasala-han kesenjangan yang paling mencuat di Indonesia antara lain kesenjangan antar daerah, antar sektor, antar wilayah antara Kawasan Barat Indonesia dengan Kawasan Timur Indonesia, antara perkotaan dan perdesaan. Kesenjangan tersebut tidak hanya dipandang dari aspek ekonomi, tapi juga aspek non ekonomi (Lutfi Muta'ali, 2014 : 18)

Bentuk kesenjangan yang beberapa periode belakangan ini menjadi isu penting di Indonesia, telah menghasilkan suatu konsekuensi berupa pemusatan hasil pembangunan pada sebagaian wilayah. Hal ini pada akhirnya mengakibatkan terdapat beberapa wilayah yang tertinggal dibanding wilayah lainnya. Tidak hanya dalam budaya dan pembangunannya secara fisik, namun juga masalah pendidikannya.

Pendidikan merupakan usaha sadar untuk menyumbangkan kemampuan usaha manusia dalam rangka memajukan aktivitas.
Pendidikan sebagai suatu aspek yang menyumbangkan sumber daya manusia yang dimaksudkan untuk meningkatkan pengetahuan dan kemampuan seseorang dalam berbagai kegiatan, juga diharapkan mampu membuka cara berpikir ekonomis dalam arti mampu mengembangkan potensi yang ada untuk memperoleh hasil semaksimal mungkin.

Pengembangan pendidikan merupakan salah satu prioritas utama dalam agenda pembangunan nasional. Karenaitu, pemerintah berkewajiban untuk memenuhi hak setiap warga negara dalam memperoleh layanan pendidikan guna meningkatkan kualitas hidup Bangsa Indonesia sebagaimana diamanatkan oleh UUD 1945, yang mewajibkan pemerintah bertanggung jawab dalam mencerdaskan kehidupan bangsa dan menciptakan kesejahteraan umum. Demikian juga warga negara di daerah terpencil atau tertinggal serta masyarakatnya berhak memperoleh pendidikan layanan khusus (pasal 5 ayat 2, 3 dan 4).

Jorong Bukit Lintang adalah salah satu Jorong yang terdapat di 


\begin{tabular}{|l|l|l|l|l|l|l|}
\hline No. & $\begin{array}{c}\text { Tingkat } \\
\text { Pendidik- } \\
\text { an }\end{array}$ & $\begin{array}{c}\text { Peri- } \\
\text { ode }\end{array}$ & $\begin{array}{c}\text { Jumlah } \\
\text { Anak }\end{array}$ & selesai & Putus & $\begin{array}{c}\text { Tidak } \\
\text { Sekolah }\end{array}$ \\
\hline 1. & SD & $\begin{array}{l}2009- \\
2015\end{array}$ & 35 & 21 & 9 & 5 \\
\hline 2. & SMP & $\begin{array}{l}2012- \\
2015\end{array}$ & 18 & 3 & 6 & 9 \\
\hline 3. & SMA & $\begin{array}{l}2012- \\
2015\end{array}$ & 12 & - & - & 12 \\
\hline \multicolumn{2}{l}{ Jumlah } & 65 & 24 & 15 & 26 \\
\hline
\end{tabular}

Nagari Malampah Kecamatan Tigo Nagari Kabupaten Pasaman. Jorong Bukit Lintang ini merupakan daerah tertinggal dilihat dari segi permasalahan dasarnya yaitu persoalan perekonomian (kemiskinan penduduk), sumber daya manusia yang rendah, prasarana/infrastruktur yang kurang, aksesibilitas untuk mencapai pusat-pusat pelayanan dasar yang minim (keputusan Wali Nagari Malampah 2015). Jorong ini terletak di kaki Gunung Pasaman yang sangat susah di tempuh oleh kendaraan sepeda motor terlebih lagi mobil yang membuat Jorong ini makin tertinggal baik itu masalah pembangunan, pendidikan maupun bantuan-bantuan sosial lainnya.

Berdasarkan observasi awal di Jorong Bukit Lintang yang sebagian besar pendududuknya petani, masyarakat Jorong Bukit Lintang banyak yang tidak menempuh pendidikan formal, selanjutnya ada lagi yang menempuh pendidikan formal tetapi hanya sampai pada tingkat Sekolah Dasar (SD) kemudian tidak melanjutkan lagi ke tingkat atas. Pendidikan masyarakatnya tergolong rendah, dapat dikatakan bahwa kondisi pendidikan masyarakat Jorong Bukit Lintang masih memprihatikan. Hal ini dapat dilihat di SD, SMP dan SMA dimana angka statistik putus sekolah lebih banyak dari pada yang tamat, dapat dilihat pada tebel dibawah ini:

Tabel Tabel 1.1
Angka Statistik Putus Sekolah di Jorong Bukit Lintang

Sumber: Profil Nagari Malampah 2015

Observasi sementara peneliti, terdapat banyak faktor yang melatar belakangi rendahnya tingkat partisipasi masyarakat Jorong Bukit Lintang dalam dunia pendidikan. Seperti, Jorong Bukit Lintang Nagari Malampah menghadapi kendala berupa minimnya infrastruktur pendidikan, hanya terdapat satu Sekolah Dasar (SD) di Jorong Bukit Lintang itupun dengan lokal yang terbatas dan untuk sekolah lanjutan seperti SMP dan SMA berada di pusat kecamatan yang letaknya jauh dari Jorong Bukit Lintang, minimnya infrastruktur ini menjadi faktor penghambat masyarakat Jorong Bukit Lintang memperoleh pendidikan formal. Hal ini bukan sepenuhnya kesalahan masyarakat, akan tetapi merupakan persoalan bersama (nasional). Oleh karenanya, perlu perhatian berbagai pihak terkait Pemerintah Pusat, Pemerintah Daerah (provinsi, kabupaten/kota), dan para pemangku kepentingan lainnya. Melalui upaya tersebut diharapkan secara bertahap masyarakat daerah tertinggal Jorong Bukit Lintang terentas dari ketertinggalannya, usunya di bidang pendidikan u...ingga bisa mengatasi ermasalahan lainnya.

Berdasarkan permasalahan tersebut peneliti akan mengadak penelitian. Tujuan dari penelitian adalah :

1. Untuk mengetahui faktor-faktor penghambat masyarakat daerah tertinggal dalam memperoleh pendidikan formal.

2. Untuk mengetahui sejauh mana peran pemerintah daerah/lembaga masyarakat dalam pendidikan 
masyarakat daerah tertinggal di Jorong Bukit.

\section{METODE PENELITIAN}

Penelitian ini merupakan penelitian Deskriptif Kualitatif. Sugiyono (2007) penelitian deskriptif adalah suatu bentuk penelitian yang paling dasar ditujukan untuk mrndiskripsikan atau mengambarkan fenomena yang ada, baik fenomena yang bersifat alamiah ataupun rekayasa manusia. Tika (1997 :115) menjelaskan bahwa deskriptif kualitatif diperlukan untuk menjelaskan fenomena-fenomena yang bersifat sosial.

Karakteristik informan : 1) orang tua yang memliki anak tidak sekolah, 2) orang tua yang memiliki anak putus sekolah, 3) orang tua yang memliki anak usia sekolah SD,SMP dan SMA. Jika informan yang sedikit belum mampu memberikan data yang memuaskan, maka peneliti mewawancarai KK yang lain dengan karakteristik yang telah ditentukan, hingga data yang diperoleh benarbenar mendapatkan informasi yang akurat, peneliti mengambil informan kunci yaitu anak usia sekolah yang peneliti temui di Jorong Bukit Lintang, dan untuk menjawab pertanyaan dari peran pemerintah/lembaga masyarakat dalam pendidikan masyarakat Jorong Bukit Lintang peneliti mewawancarai Kepala Dinas Pendidikan Kabuaten Pasaman, Wali Nagari Malampah, Kepala Jorong Bukit Lintang, Guru yang mengajar di Jorong Bukit Lintang dan tokoh masyarakat atau Niniak Mamak yang ada di Jorong Bukit Lintang.

\section{HASIL DAN PEMBAHASAN}

Faktor-Faktor Penghambat Masyarakat Didaerah Tertinggal Memperoleh Pendidikan Formal

1. Pandangan Masyarakat Terhadap Pendidikan

masyarakat daerah tertinggal di Jorong Bukit Lintang, mempunyai pandangan bahwa pendidikan kurang begitu penting dan hanya memilih pendidikan yang seperlunya bagi kehidupan mereka. Karena, dipengaruhi oleh beberapa faktor seperti :

Pertama, tingkat pendidikan orang tua mempengaruhi pola pikir mereka terhadap pentingnya pendidikan. Orang tua yang hanya tamat Sekolah Dasar atau tidak tamat Sekolah Dasar di Jorong Bukit Lintang cenderung kepada hal-hal tradisional dan kurang menghargai arti pentingnya pendidikan. Para orang tua beranggapan sekolah hanya membuang waktu, tenaga dan biaya, mereka juga beranggapan anak lebih baik ditunjukan kepada hal-hal yang nyata seperti anak laki-laki belajar berkebun dan mengolah sawah membantu orang tua dalam berusaha, sedangkan bagi anak perempuan lebih diutamakan belajar urusan rumah tangga supaya nantinya anak tidak canggung saat setelah berkeluarga. Itulah manfaat yang nyata bagi mereka, lagi pula sekolah harus melalui seleksi ujian yang ditempuh dengan waktu yang panjang dan amat melelahkan.

Kedua, pengalaman mempengaruhi pola pikir masyarakat terhadap pentingnya pendidikan. Di Jorong Bukit Lintang ada masyarakatnya yang berpendidikan tinggi seperti tamatan SMA dan S1. Tetapi, masih belum mampu mencari pekerjaan yang lebih baik dan belum mampu memberikan dampak positif terhadap keluarga terutama terhadap 
kemajuan ekonomi keluarganya. Kondisi demikianlah yang mempengaruhi pola pikir masyarakat Jorong Bukit Lintang untuk memperoleh pendidikan formal.

Ketiga, ekonomi mempengaruhi pola pikir masyarakat terhadap pentingnya pendidikan. Para orang tua di Jorong Bukit Lintang tidak melanjutkan pendidikan anaknya ke jenjang yang lebih tinggi karena dihadapkan pada faktor ekonomi, dikarenakan para orang tua di Jorong Bukit Lintang merasakan semakin tinggi jenjang pendidikan maka semakin mahal pula biaya pendidikan sedangkan pendapatan hanya mencukupi untuk kebutuhan seharihari.

2. Faktor Jarak dari Tempat Tinggal Kesekolah

Pertama, sarana pendidikan yang ada di Jorong Bukit Lintang masih sangat terbatas yaitu hanya ada satu buah Sekolah Dasar (SD), itupun jaraknya cukup jauh dari rumahrumah masyarakat. Selanjutnya, untuk sekolah Menengah Pertama (SMP) Dan Sekolah Lanjutan (SMA) yang memang belum ada di Jorong Bukit Lintang, untuk SMP berada di pusat nagari malampah dengan jarak tempuh $8 \mathrm{~km}$, sedangkan untuk ke SMA harus ke ibu Kota Kecamatan dan jaraknya sangat jauh dari Jorong bukit Lintang $15 \mathrm{~km}$, dengan jarak tempuh yang demikian jauh masyarakat Jorong Bukit Lintang mengalami kendala tidak adanya sarana transportasi yang tersedia di Jorong ini yang memudahkan masyarakat mengakses pendidikan formal. Masyarakat Jorong Lintang harus memutar jalan ke Jorong Kampung Tabek karna disana ada trasportasi berupa ojek, biaya sewa ojek biasaya ke SMP Rp.10.00013.000 dan untuk ke SMA masyarakat harus membayar Rp.15.000-20.000.

Kedua, Rusaknya sarana dan prasarana jalan di Jorong Bukit Lintang. Seperti, Jembatan Batang Landu yang menghubungkan tiga kampung ke kampug bukit lintang membuat msyarakat Jorong Bukit Lintang semakin susah mengakses pendidikan formal. Bagi masyarakat yang mempunyai anak usia Sekolah Dasar rusaknya sarana jalan ini menghambat masyarakat untuk melanjutkan sekolah. Tinggal di kaki pegunungan cuaca tidak dapat ditentukan buruknya cuaca dipegunungan dapat menambah debet sungai, sungai akan meluap dan sewaktu-waktu dapat mengahanyutkan anak-anak yang sedang menyeberang untuk pergi ke sekolah. Hal ini yang sering membuat para orang tua di Jorong Bukit Lintang yang memiliki anak usia sekolah SD kwatir dan tidak jarang dari mereka menyuruh anaknya untuk berhenti sekolah.

3. Faktor Keinginan/Motifasi Anak untuk Sekolah

Pertama, kurangnya motivasi dari orang tua. Cara berfikir masyarakat yang lebih memprioritaskan bekerja demi menghasilkan uang dan kurang memperhatikan pendidikan anak, yang mengakibatkan anak-anak beranggapan bahwa pendidikan tidaklah begitu penting,

Kedua, lingkungan tempat tinggal. Di Jorong Bukit Lintang kebanyakan anak-anak usia sekolah yang seharusnya sekolah namun tidak sekolah karena sudah terbiasa bekerja dan mencari uang sendiri, sehingga mempengaruhi anak-anak lainnya yang sedang sekolah. Senada dengan hasil penelitian Rusmiati (2016:11) yaitu banyaknya anak usia sekolah 
sudah bekerja disuatu lingkungan akan berpengaruh terhadap anak yang sedang menempuh pendidikan karena bisa saja mereka terpengaruh oleh lingkungan dan membuat mereka malas untuk datang ke sekolah.

Ketiga, Selain itu, tidak jarang di daerah pedalaman anak memiliki masalah khusus seperti rendahnya hasil belajar disekolah, dipengaruhi oleh faktor kurangnya sarana pendidikan dan kembali lagi ke lingkungan kelurga, orang tua yang disibukan dengan aktivitas bekerja dan mencari uang setiap harinya sehingga kurang memperhatikan perkembangan pendidikan anaknya. Bagi masyarakat Jorong Bukit Lintang sudah selesai tugasnya apabila sudah menyekolahkan anaknya, dan mereka tidak mempedulikan lagi masalah pendidikan yang dihadapi anak disekolah.

4. Keterlibatan Anak Memenuhi Kebutuhan Ekonomi Kelurga

Di Jorong Bukit Lintang yang mayoritas pekerjaan masyarakatnya sebagai petani padi dan pekebun jagung, keterlibatan anak membantu ekonomi kelurga sudah menjadi hal yang sangat biasa terjadi di lingkungan masyarakat.

Masyarakat yang memiliki lahan luas dengan kepemilikan sendiri lebih sering memanfaatkan tenaga anak untuk mengarap lahan dari pada menyewa buruh tani untuk membantu, dengan pertimbangan menghemat biaya produksi sehingga hasil panen dapat dinikmati kelurga sepenuhnya.

Kebudayaan yang sudah terjalin lama di kalangan masyarakat tertinggal Jorong Bukit Lintang, bagi anak perempuan jika sudah bisa bekerja rumah tangga selain menikah di usia dini untuk mengurangi beban rumah tangga kelurga, biasanya mereka pergi merantau mengikuti tetangga-tetangga terdekat yang masyarakat anggap sudah sukses di rantau orang. Dikalangan masyarakat Jorong Bukit Lintang, jika anak mereka sudah bekerja diluar daerah di anggab sudah kaya dan ekonomi mereka sudah mencukupi dibandingkan dengan masyarakat lainnya, walaupun kenyataannya tidak begitu nyata. Pemikiran seperti ini yang membuat para orang tua anak memilih untuk tidak melanjutkan sekolah anak mereka ke jenjang yang lebih tinggi khususnya bagi anak perempuan.

5. Peran Pemerintah Daerah Dan Lembaga Masyarakat Dalam Pendidikan Masyarakat Tertinggal Jorong Bukit Lintang

Peran Pemerintah Daerah agari Malampah terhadap kemajuan sndidikan masyarakat tertinggal di Jorong Bukit Lintang, belum sepenuhnya baik.

Pemerintah daerah beberapa tahun terakhir ini belum pernah melakukan penyuluhan tentang pendidikan langsung ke Jorong Bukit Lintang, dan tidak adanya sumbangan dari pemerintah setempat untuk memajukan pendidikan masyarakat tertinggal di Jorong Bukit Lintang. Hal ini dikarenakan jauhnya akses menuju Jorong Bukit Lintang. " amun, Pemerintah nagari setiap hunnya berusa mengirim Mahasiswa KKN dan Tim Ramadhan ke Jorong Bukit Lintang yang bertujuan mingkatkan minat dan pengetahuan masyarakat tarhadap pendidikan, tetapi dilatar belakangi oleh sikap masyarakat yang susah untuk menerima pendatang baru di lingkungan mereka, membuat program pemerintah ini tidak terlaksana seperti yang diharapkan 
oleh pemerintah nagari. Masyarakat Jorong Bukit Lintang menolak Mahasiswa KKN dan Tim Ramadhan dengan alasan takut anak-anak mereka nantinya terpengaruh oleh dunia luar.

Peran lembaga masyarakat dalam pendidikan masyarakat Jorong Bukit Lintang, hanya bisa sekedar menfasilitasi kebijakan-kebijakan yang diberikan oleh pemerintah darah.

Kurangnya tenaga pendidik membuat sekolah yang ada di Jorong Bukit Lintang kesulitan menjalankan perannya terhadap pendidikan masyarakat sekitar, pihak sekolah membentuk ketua Komite guna membantu masyarakat lebih mudah mengakses pendidikan, dan salah satu cara lain yang dilakukan oleh pihak sekolah adalah mengundang masyarakat dan para orang tua untuk menghadiri rapat sekolah. Namun, dihadapkan oleh sikap masyarakat dan para orang tua yang selalu sibuk mencari uang dan kurang memperhatikan pendidikan anak-anak mereka.

Jadi kurangnya peran pemerintah dan lembaga masyarakat terhadap pendidikan menjadi faktor penghambat tersosialisasinya nuansa pendidikan bagi masyarakat tertinggal di Jorong Bukit Lintang.

\section{PENUTUP}

\section{Kesimpulan}

Berdasarkan hasil penelitian dan pembahasan, maka dapat ditarik kesimpulan sebagai berikut :

1. Faktor penghambat masyarakat tertinggal di Jorong Bukit Lintang memperoleh pendidikan formal adalah rendahnya pendangan masyarakat tertinggal di Jorong Bukit Lintang akan pentingnya pendidikan, jauhnya jarak tempuh dari rumah ke sekolah, tidak adanya sarana transportasi dan rusaknya sarana prasara jalan yang ada di Jorong Bukit Lintang, rendahnya motivasi anak untuk sekolah, dan anak sangat berperan dalam memenuhi kebutuhan ekonomi keluarga terutama dalam membantu orang tua untuk mengarap sawah atau ladang, sehingga menghambat anak untuk memperoleh pendidikan formal.

2. Peran pemerintah daerah dan lembaga masyarakat terhadap pendidikan masyarakat Jorong Bukit Lintang belum memberikan dampak dan pengaruh yang optimal terhadap kemajuan pendidikan di Jorong Bukit Lintang. Ada beberapa hal yang menyebabkan tidak optimalnya peran pemerintah daerah dan lembaga masyarakat yaitu letak geografis Jorong Bukit Lintang yang jauh dari pusat pemerintahan, masyarakat disibukan bekerja dan kurangnya tenaga pendidik menjadi faktor penghambat tersosialisasinya nuasa pendidikan formal di daerah tertinggal Jorong Bukit Lintang Nagari Malampah.

\section{Saran}

Setelah melakukan penelitian ini, ada beberapa saran yang ingin penulis berikan yaitu:

1. Diharapkan pada pemangku kepentingan di bidang pendidikan melalui program-program nyata untuk memotivasi masyarakat Jorong Bukit Lintang agar lebih meningkatkan pendidikannya.

2. Diharapkan pada pemerintah baik di Kecamatan, Kabupaten bahkan pemerintah pusat, kiranya perlu memperhatikan sarana dan prasarana di daerah pedalaman 
khusnya Jorong Bukit Lintang seperti jalan dan jembatan yang rusak parah dan menjadikan masyarakatnya susah menuju pusat Nagari.

3. Diharapkan pada pemerintah baik di Nagari, Kecamatan, Kabupaten bahkan pemerintah pusat agar lebih kontiniu dan berkesinambungan melakukan penyuluhan tentang pendidikan bagi masyarakat tertinggal khususnya masyarakat

4. Jorong Bukit Lintang sihingga dapat merubah pola pikir masyarakatnya terhadap pendidikan.

5. Bapak atau Ibuk di Jorong Bukit Lintang sebagai orang tu yang bertangung jawab terhadap anaknya, agar memberikan motivasi kepada anak untuk kepentingan sekolah dan tidak terlalu membebani mereka memenuhi ekonomi keluarga.

\section{DAFTAR PUSTAKA}

Malik Hermen.2013. Fajar Kebangkitan Pendidikan Daerah Tertinggal. Jakarta: LP3ES.

Muta'ali Lutfi.2014. Pengembangan Wilayah Tertinggal. Yogyakarta: Badan Penerbit Fakultas Geografi (BPFG).

Profil Nagari Malampah.2015, Dokumen Desa.

Sugiono.2007.Metode Penelitian Pendidikan. Bandung : Alfabeta.

Tika, Moh. Pabundu.(1997). Metode Penelitian Geografi. Jakarta : Gramedia. 